UDC: 821.134.2(899).09-31 Mella D.

DOI: https://doi.org/10.18485/beoiber.2018.2.1.10

\author{
Giuseppe Gatti Riccardi ${ }^{1}$ \\ Universitá degli Studi Guglielmo Marconi - Roma \\ Universitá degli Studi della Tuscia - Viterbo \\ Italia
}

\title{
LOS MATICES DEL DOLOR EN LA NARRATIVA URUGUAYA DEL NUEVO SIGLO. SEPARACIÓN Y MUERTE COMO PÉRDIDAS ÍNTIMAS: NOVIEMBRE, DE DANIEL MELLA
}

\begin{abstract}
Resumen
En el marco de la variedad genérica y temática que caracteriza la prosa de ficción en el área rioplatense del comienzo del nuevo siglo, nuestro estudio se centra en el análisis de una novela de rasgos introspectivos, Noviembre, que el escritor montevideano Daniel Mella publicó en el año 2000. Se analizará, en primer lugar, el modo en que el escritor consigue mantenerse coherente con los macrotemas de su narrativa anterior y logra ofrecer al lector una novela que se centra en el dolor del ser humano, pero alejándose de los traumas de la dictadura descritos en las ficciones rioplatenses de la "postmemoria". Lejos de los estallidos de agresividad y brutalidad física de su producción precedente (Derretimiento), un texto como Noviembre plantea una reflexión - sin ofrecer respuestas - sobre las varias expresiones del dolor íntimo que surge de traumas afectivos y que provoca, como resultado, la pérdida del sentido de la realidad.

En lo que se refiere a la teoría que se utilizará como soporte de la investigación, se propone una trabazón entre unos estudios canónicos (como los de Sigmund Freud dedicados al análisis del funcionamiento de la psique humana en relación con la imposibilidad del manejo del dolor extremo), algunas teorías psicoanalíticas de interés actual, como las de Juan David Nasio, y los estudios de tipo sociológico de Hartmut Rosa, sin descuidar las investigaciones sobre los principios de geopoética que Gaston Bachelard aplica a la dialéctica entre la muerte y el agua.

Palabras clave: Daniel Mella, literatura uruguaya contemporánea, Noviembre, narrativa de introspección.

\section{THE NUANCES OF PAIN IN THE URUGUAYAN NARRATIVE OF THE NEW CENTURY. SEPARATION AND DEATH AS INTIMATE LOSSES: NOVEMBER, BY DANIEL MELLA}

\author{
Abstract \\ 1 giuseppe_gatti@hotmail.com / g.gatti@unimarconi.it
}


Within the framework of the generic and thematic variety that characterizes fictional prose in the Río de la Plata area of the beginning of the new century, our study focuses on the analysis of a novel of introspective traits, November, published in 2000 by the Montevidean writer Daniel Mella. We will first analyze the way in which the writer manages to keep coherent with the macrothemes of his previous narrative and write a novel based on the pain of the human being, moving away from the traumas of the dictatorship described in the so-called "novels of Postmemory". Far from the aggressiveness and physical brutality of its previous production (such as Derretimiento), a novel like Noviembre proposes a reflection without offering answers - on the various expressions of intimate pain that arises from affective traumas and that, as a result, causes the loss of the meaning of reality.

Regarding the theory that we will use as support for our research, we propose a link between some canonical studies (like those of Sigmund Feud dedicated to the analysis of the functioning of the human psyche in relation to the impossibility of handling extreme pain), some psychoanalytic theories of current interest, such as those of Juan David Nasio, and the sociological studies of Hartmut Rosa; finally, we will use some researches on the principles of geopoetics that Gaston Bachelard applies to the dialectic between death and water.

Key words: Daniel Mella, contemporary Uruguayan literature, Noviembre, narrative of introspection.

¿Qué mayor dicha para dos enamorados que esa honrada consagración de su cariño, libertado ya del vil egoísmo de un mutuo amor sin fin ninguno y, lo que es peor para el amor mismo, sin esperanzas posibles de renovación?

(Horacio Quiroga, "La gallina degollada”)

$Y$ esas cosas no van a suceder en un pasado aceptable y que yo pueda poblar a mi gusto. Van a estar -o va a estar su consecuencia- frente a mí, contra mí, tratando, empecinadas, maquinalmente, de arrastrarme al centro de su angustia, a esa profundidad húmeda, maloliente, helada, donde tienen que vivir los adultos que fueron condenados.

(Juan Carlos Onetti, Juntacadaveres)

\section{1 - Cerrando el círculo de la primera trilogía}

Desde el comienzo de la década actual, la prosa de ficción del área rioplatense está exhibiendo una notable variedad temática y genérica, que va desde la llamada "literatura de la posmemoria", vinculada con una rememoración indirecta de los eventos de las dictaduras militares (pensemos, a mero título de ejemplo, en dos novelas argentinas 
como Los topos, de Félix Bruzzone, de 2008, o Una misma noche, de Leopoldo Brizuela, de 2012), al relato policial, protagonizado por detectives cuyos rasgos remiten a los "héroes sucios" del hard boiled norteamericano (destaca, en ese ámbito, la trilogía del uruguayo Hugo Burel compuesta por El caso Bonapelch, de 2014, Montevideo Noir, de 2015, Sorocabana Blues, de 2017).

En este panorama literario apenas esbozado, se colocan, además, unas narraciones cuyo eje apunta al conocimiento, al menos parcial, de la intimidad anímica de los protagonistas. $Y$ es esta la línea temática en la que se centra nuestro análisis, dedicado al estudio de la novela Noviembre, que el escritor y periodista uruguayo Daniel Mella (Montevideo, 1976) publicó, en su primera versión, con tan solo 24 años en el año 2000, y que representa el cierre de una etapa literaria inicial que el autor dedicó integralmente al género de la novela.

La colocación cronológica de Noviembre en el marco de la producción narrativa de Mella asigna al texto el rol de "narración-umbral", pues con ella se concluye una fase de intensa actividad creativa que se había inaugurado ya en la década de los noventa, cuando había visto la luz su primera obra extensa de ficción, Pogo (1997). Solo un año más tarde, se publica Derretimiento, una novela de fuerte impacto emotivo, que marca un cambio de rumbo en la narrativa nacional de la fase de tránsito al nuevo siglo y que en su momento - llevó a la crítica literaria a establecer un vínculo temático y formal entre las dos primeras novelas de Mella y la obra de ficción de Brett Easton Ellis. A partir de la publicación de Derretimiento se fue, además, consolidando la adscripción de la narrativa de Mella a un grupo heterogéneo de jóvenes escritores uruguayos definidos como "los crueles": un conjunto de narradores que empiezan a afirmarse ya en la última década del siglo XX y que - a partir del ejemplo de la "cruel prosa poética" de Rafael Courtoisie (1958) - incluye a autores nacidos entre los años sesenta y setenta del siglo pasado (pensemos, entre varios nombres posibles, en Gustavo Escanlar, 1962-2010, Gabriel Peveroni, 1969, y en autores más jóvenes como Horacio Cavallo, 1977, o Agustín Acevedo Kanopa, 1985).

Desde el punto de vista de la cronología bibliográfica de Mella, Noviembre se coloca en el momento de cierre de esta primera etapa creativa del autor, después de la cual se inaugura una larga pausa, que se interrumpe solo en 2008 con el regreso de Mella al género del cuento, cuando ve la luz la recopilación El descontento y la promesa $(2008)^{2}$. El silencio prolongado de Mella se extiende durante una década, periodo que coincide con la larga estadía del escritor en Nueva York: fue en la ciudad estadounidense donde se dedicó a la lectura de Shakespeare y a intentar escribir teatro en inglés. A lo largo de esos diez años, se verifica en el narrador montevideano un proceso de radical

2 En lo que se refiere a bibliografía de Mella de los primeros años del siglo XXI, a El descontento y la promesa (2008) sigue su más reciente libro de relatos, Lava, que en 2013 fue galardonado con el Premio Bartolomé Hidalgo. La novela El hermano mayor (2016) es hasta el momento su más reciente publicación de ficción. 
reelaboración interior de su actividad como escritor; un volver a pensar el ejercicio de la escritura desde una perspectiva que huye no de la responsabilidad hacia el lector, pero sí de la esclavitud de la creación y de la presión de formar parte de una cadena de intereses comerciales, tal como el propio Mella afirma en una entrevista de marzo de 2017 concedida a Daniela Bluth: “Creo que [en esos años] se murió una parte de mí, el escritor, ese del que estábamos hablando, ese que se angustia terriblemente por su próximo libro" (Bluth 2017).

La fase de redacción de la primera versión de Noviembre, en el año 2000, muestra esta "muerte del escritor" a la que hace referencia Mella: el libro marca, desde el punto de vista cronológico, el límite superior de una etapa en que ese peso de la esclavitud de la creación se había hecho insoportable. Mella siente que es el engranaje de una maquinaria, que no controla más los tiempos de la creación literaria y que depende demasiado de la palabra escrita. La novela es, entonces, el documento de cierre de un periodo vital en que la tarea de escribir se vuelve al mismo tiempo el espacio de la dicha y del encierro, tal como observa Rafael Courtoisie cuando reflexiona acerca del ejercicio de la escritura:

No hay en el planeta de la lengua narrativa, más libertad que la del esclavo. Los escritores son esclavos de la palabra. Cada palabra es un eslabón de la cadena que une al hacedor del decir con su empeño, con su memoria y su viento. [...] El hombre se vuelve Dios cuando relata, pero su divinidad resulta atroz y no alcanza el espejo de la dicha. [...] Tarea de esclavos o dioses. Esclavitud gloriosa, orgullo, placer soterrado, condición humilde, inconfesablemente grandiosa y pura de mancillar páginas, tragar letras, escupir signos sobre el hambre voraz del mundo en blanco (Courtoisie 2009: 282-283).

En los años transcurridos en los Estados Unidos, Mella se libera - en parte - de la esclavitud de la palabra a la que alude Courtoisie; si, por una parte, es cierto que al regresar a Montevideo no deja de ser escritor, y sigue "mancillando páginas" y "escupiendo signos sobre el hambre voraz del mundo en blanco", también parece evidente que ya ha tenido acceso a una dimensión anímica en que no se angustia más por el éxito inmediato de su próximo libro.

Ahora bien, desde el punto de vista de los macrotemas presentes en nuestra "novela-umbral", el que el texto pertenece a la primera fase de la trayectoria literaria de Mella es una evidencia que se desprende de la presencia inminente y acechante de la crueldad, el espanto y una cierta atmósfera sutilmente mórbida. Así como Pogo (1997) se había caracterizado por ser una novela sobre la soledad, el dolor del ser humano y varias expresiones del dolor mismo, y así como dos años más tarde, en Derretimiento (1999) el escritor montevideano había focalizado la atención del lector en la ferocidad humana que marca la trayectoria vital de un psicópata, la lectura de Noviembre obliga a repensar el modo en que el dolor se abre paso en la vida humana. En la línea inaugurada a finales de los noventa, Mella plantea de nuevo al lector una superposición inextricable entre el dolor y el horror, tal como el mismo autor subraya en el breve resumen que acompaña la 
presentación de Noviembre, en la página web del autor: “Para Ana y Guzmán todo está más o menos previsto: inseguridad, temor, ocio, fracaso, evasión. Pero no contaron con el dolor. El insoslayable, imprevisible, inaceptable dolor; y su aliado, el horror" (Mella 2016).

En Noviembre, el lector se confronta con una narración en tercera persona que sigue de manera pormenorizada las andanzas del protagonista masculino, Guzmán, un hombre que se enfrenta a una reciente separación conyugal (de la Ana de la cita anterior), y que pasa los fines de semana con su hija de cinco años, Maite. El escenario de la trama coincide con el balneario de Neptunia, en la llamada Ciudad de la Costa, un espacio geográfico de límites borrosos en el que vive ese matrimonio muy joven que desde hace poco tiempo experimenta la soledad, la inseguridad emotiva y la angustia debidas a la reciente separación: una soledad todavía no completa ni radical, que implica no solo aprender cómo se vive y se trabaja bajo los nuevos presupuestos vitales, sino también cómo manejar - cada uno a solas - el cuidado de la pequeña Maite. Sobre la base de estos presupuestos temáticos, el narrador omnisciente que presenta la historia ofrece a la mirada del lector una suerte de "persecución silenciosa", que remite a la de una cámara cinematográfica llevada al hombro por el autor del relato, quien sigue paso a paso los desplazamientos de su personaje principal.

En el año 2010, el texto de la novela primigenia, publicado en 2000 en Montevideo por la editorial Alfaguara, vive una experiencia de revisión radical por parte de su autor, y vuelve a renacer como una criatura nueva: Mella se dedica a un proceso de reelaboración de forma y contenido, llevando a cabo una suerte de plagio autorizado, perpetrado por el autor sobre su propia obra. El resultado es una novela que adquiere una nueva existencia, ya independiente de su versión primera, tal como el propio escritor subraya en una nota a la edición revisada que hace de breve prólogo a la nueva versión: "La revisión de Noviembre me llevó a podarle treinta o más páginas. Digo podar porque el libro tiene vida y nuestra relación es misteriosa y no sé si en un futuro de estos mismos cortes crecerá algo nuevo" (Mella 2010: 9).

En las páginas que siguen se intentará centrar la atención en tres ejes - en comunicación entre sí - que pueden resumirse en: a) el análisis de los mecanismos de gestión del sufrimiento anímico por parte de los protagonistas, observando en particular el rol de la rememoración en la elaboración del trauma; b) el análisis del funcionamiento de la psique humana en relación con la imposibilidad del manejo del dolor extremo (la muerte de seres queridos), que se convierte en una tensión imposible de modular y controlar; en este ámbito, se inserta la dialéctica entre la muerte y el agua, que se intentará examinar sobre la base de principios de geopoética; c) las estrategias formales de narración que Mella adopta en el texto, haciendo hincapié en cómo un cierto rasgo identitario de la escritura del autor se convierte en la herramienta formal necesaria para expresar el estado íntimo de sus criaturas de ficción: se alude aquí al desplazamiento del clímax de la narración a espacios marginales del texto; es este un mecanismo frecuente en 
la prosa de Mella: un "desplazamiento del centro" al que se une la deliberada indeterminación de la información transmitida.

\section{II - Convivir con una reciente soledad: la separación}

La estructura narrativa de Noviembre se caracteriza por una primera parte marcada por una atmósfera apacible, casi monótona, que funciona como prólogo a la muerte sin explicación de la pequeña Maite. Una mañana de un domingo casi veraniego el padre se despierta y descubre que la niña no respira; es a partir de este momento cuando una sensación de extrañeza invade al lector: el padre se acerca al cuerpo de la pequeña, comprueba que no respira y sin embargo no hay, en sus actitudes y reacciones, ninguna manifestación evidente que transmita al lector la certeza de que la nena está muerta. Los tiempos de los rituales matutinos de Guzmán, de su charla con un conocido que aparece inesperadamente en la casa esa misma mañana - se mantienen inalterados o, incluso, se alargan; nada parece haber acontecido en la casa y a la sensación inicial de extrañeza se empieza a añadir una sensación de incomodidad: Mella coloca en el relato "algo que oscila entre un impulso al rechazo, como un deseo de decir "esto no puede ser", y el hecho de que no hay nada que realmente viole los límites de lo normal, o de lo que en general consideramos normal" (Trujillo 2004: 195).

Sobre la base de esta premisa, fundada en mensajes transmitidos al lector de forma incompleta o ambigua, el relato se caracteriza por la presencia constante en el texto de reflexiones introspectivas del personaje masculino acerca de su estado anímico, como consecuencia de este doble trauma: la separación, que todavía no ha sido procesada, y la pérdida de su única hija. En lo que se refiere al análisis introspectivo relativo a los vaivenes de la relación sentimental, el mecanismo dominante en el texto es el del recuerdo: volver hacia atrás se vuelve una forma casi sólida de viaje, un recorrido hacia el pasado compartido con Ana, su ex-esposa y madre de la pequeña Maite. En la novela, Mella enfoca el proceso de rememoración de Guzmán desde el punto de vista del modelo freudiano que analiza las distintas tipologías de neuronas y sus funciones; en "Proyecto de psicología" el científico austriaco subdivide en tres grupos las neuronas y se detiene en particular en la conexión que existe entre los primeros dos: el primero sería el bloque "localizado en la periferia del yo, [que] tiene por función percibir las estimulaciones del mundo externo" (Freud 1991: 326). El segundo bloque es el que más nos interesa para nuestro estudio, pues remite a un conjunto de neuronas que actúan en el cerebro precisamente como "instrumentos de conservación" del recuerdo; se trata de un grupo "situado en el centro del yo, compuesto de neuronas del recuerdo, [que] tiene por función no percibir sino conservar la huella de los acontecimientos fuertes" (Freud 1991: 327).

Este grupo, que en el sistema freudiano se convierte en el "sistema inconsciente", es el responsable - a nuestro juicio - de que la memoria del protagonista viaje 
repetidamente hacia atrás: todo el texto, de hecho, se construye en torno a una serie de tambaleos temporales de la psique; del momento presente la memoria se desliza, por compensación, hacia situaciones y vivencias de un pasado compartido y que todavía permanece vivo. A partir de estos tránsitos por la dimensión temporal del relato, la narración se deshilvana según un esquema que marca toda la producción literaria de Mella: dejar que la indeterminación de lo dicho y la indefinición del momento tópico de la trama se apoderen de las páginas escritas.

No hay en sus relatos respeto por el esquema aristotélico de inicio, nudo y desenlace: el autor se centra en la exploración de las posibilidades del texto escrito como forma de expresión que no debe necesariamente seguir un modelo narrativo estándar: esta investigación de los modelos narrativos lo lleva a colocar los aspectos clave de la historia en momentos que no coinciden con el punto en que el lector colocaría el clímax del mismo. En todo momento, quien lee percibe que todavía quedan muchos puntos por cerrar, y esta indefinición hace posible que los textos de Mella estén impregnados de "pequeños secretos sin decir", de una "presencia latente de hipótesis posibles", como si el interés no estuviera en fijar un desenlace coherente en los finales, sino en subrayar como el centro de lo que se quiere contar se encuentra (o se puede encontrar) en otra parte de la historia.

En estos "pequeños secretos sin decir" que caracterizan la prosa ficcional de Mella es como si residiera una suerte de "negación a responder"; es decir, en el centro del dispositivo narrativo parece colocarse una especie de "hueco", que hace que el secreto de la trama se diluya y se derrame por las periferias del texto, sin dejar a quien lee certeza alguna. Esta incertidumbre plantea al lector de Noviembre ( $y$ de toda la ficción de Mella) la posibilidad concreta de suponer que las distintas hipótesis barajadas sean todas igualmente válidas, $\mathrm{y}$, al mismo tiempo, le transmite la sensación de que se puede narrar todo, pero dejando intacto el secreto último. Es esta una postura que enlaza con la línea que Jacques Derrida propone en su ensayo Passions, en el que el filósofo francés afirma que

hay en la literatura, en el secreto ejemplar de la literatura, una posibilidad de decir todo sin tocar el secreto. Cuando todas las hipótesis están permitidas, sin fondo y hasta el infinito, sobre el sentido de un texto o las intenciones de un autor [...], cuando no tiene sentido ni siquiera decidir acerca de un secreto detrás de la superficie de una manifestación textual [...], cuando es el llamado de este secreto el que sin embargo reenvía al otro o a otra cosa [...], entonces el secreto nos apasiona, incluso si no lo hay, si no existe, oculto detrás de lo que sea (Derrida 1993: 68).

Ahora bien, en la prosa de Mella conviven justamente los tres elementos: la sensación permanente de que todas las hipótesis están permitidas; la percepción de que siempre se guarda un secreto (o una parte de un secreto) detrás de la superficie del texto; 
el tambaleo continuo entre el presente y eventos del pasado. Se había aludido a este tercer punto al comienzo de este apartado; es decir, al repetido tránsito que la memoria efectúa entre el momento presente y situaciones y vivencias de un pasado compartido ( $y$ todavía vivo). Esta estrategia narrativa se hace patente, por ejemplo, en la rememoración de los primeros años de la relación de pareja entre Guzmán y Ana: el recuerdo vuelve atrás hasta la época en que el empeño de Guzmán para mantener en pie la economía familiar gracias a su propio trabajo (y sin la ayuda económica de la familia de la mujer) empieza a crear pequeñas fisuras en la relación de pareja:

Ana lo empezó a esperar con la mesa puesta y velas, a la hora que fuese. A veces la encontraba dormida en el sillón cama. Comenzó a descuidar a Maite. La dejaba sin bañar, la ponía a dormir a deshoras, la estaba convirtiendo en una llorona. Guzmán se lo hizo ver y Ana lo escuchó callada, y recurrió al apoyo de Elvira para el cuidado de la niña. Hizo todo lo posible para saciar a Guzmán cuando estaba en casa, y todo ese tiempo él fue consciente de que estaba presenciando la caída de su mujer, la de ambos. La vio desmoronarse, diminuta en su mundo enano. Ella ocultaba el exceso de su esfuerzo en una sonrisa inquebrantable y a él la potencia del espectáculo lo inmovilizó. Empezaron a negarse el contacto físico sin decirlo (Mella 2010: 39).

El texto subraya este momento, en que empieza a desmoronarse la vida de pareja de Ana y Guzmán, y pone en relación este punto de quiebre con la aceleración de la vida en la sociedad contemporánea: la competencia laboral, las presiones de carácter económico, los cambios en la atribución de los roles de responsabilidad dentro de una estructura familiar representan, en conjunto, el móvil que desata el proceso de alejamiento progresivo de los dos adultos. Se alude aquí a una aceleración generalizada, debida a la complejidad de la vida contemporánea, que abarca los ámbitos de la producción, de las comunicaciones, de las modalidades de desplazamiento, y sobre todo de las relaciones socio-familiares aplicadas a la cotidianeidad; en fin, un apresuramiento que desgasta la relación de pareja y que, en palabras de Hartmut Rosa, "muda las formas de la subjetividad humana (el mundo subjetivo) y también nuestra forma de ser en el mundo, en relación con las fuerzas trasformadoras de la aceleración tecnológica" (Rosa 2015: 45) $)^{3}$.

En la novela, la adquisición por parte del lector de la información acerca del progresivo desgaste de la vida de pareja se da paulatinamente, a través del cristal de la mirada hacia atrás de Guzmán; hay, en esta estructura narrativa, un desajuste temporal deliberado: el protagonista nos informa, hoy, de que su percepción - muy lúcida - del

3 El título original del estudio de Hartmut Rosa (que se publica por primera vez en 2010) es Alienation and Acceleration. Towards a critical Theory of Late-Modern Temporality. Se ha tenido acceso al texto gracias a una traducción al italiano del año 2015; sigue la versión en italiano que he traducido: "l'accelerazione muta le forme della soggettività umana (il mondo soggettivo) e anche il nostro essere nel mondo, in contatto con le forze trasformatrici dell'accelerazione tecnologica". 
derrumbe de su vida sentimental se remonta a los momentos mismos en que este derrumbe se empezaba a hacer concreto. Obsérvese, de hecho, cómo Guzmán era consciente de estar viendo "desmoronarse" a Ana, colocándola, "diminuta", en su mundo pequeño y claustrofóbico, un mundo "enano".

Si se desplaza cronológicamente el análisis a los meses inmediatamente posteriores a la separación, cuando la casa del protagonista, en Neptunia, ya está llena de silencios y de sombras, se observa cómo la muerte se manifiesta en la mente de Guzmán no como una materia abstracta de reflexión, sino como una presencia casi concreta, que se asocia a la nueva condición de soledad:

Con la separación, pensó en la muerte como nunca antes. Se despertaba de noche con ganas de ser fumador. O llegaba de una habitación a otra, de la cocina al comedor por ejemplo, y no encontraba a su mujer y a su hija pendientes como novias, y su mente divagaba sobre qué sucedería si una de ellas se muriese. Las divagaciones eran infértiles en todo caso y Guzmán pensaba que estaba aprendiendo. Pensaba que ese aprendizaje era semejante al que traía la vejez, a la que él ingresaba a pasos agigantados, y se sentía desnudo y suponía que se trataba de una preparación. Estaba recogiendo las armas para soportar el dolor real cuando llegara. Tocaba la muerte en el estado triste de su ropa, triste en el desorden de la casa y en la calidad de sus comidas. (Mella 2010: 44).

En esta asombrosa anticipación consciente de una tragedia venidera, la cifra de la soledad del protagonista y de su desesperanza es la muerte: el descuido de la casa, de la ropa, la comida que se vuelve cada día más pobre y de ínfima calidad representan las múltiples caras del único y tenaz fantasma que asedia la vida de Guzmán, pero sobre todo la muerte aparece casi corporizada. Se asoma como una presencia invisible que acecha y que se puede ceñir en cualquier momento en torno a uno de los dos seres de sexo femenino de su vida; de ahí que la mente del hombre fuera divagando acerca de cómo enfrentarse al dolor si una de las dos se muriese.

El dolor psíquico del protagonista es, en realidad, un conjunto de uestados de dolor" que fraccionan el dolor mismo en tres momentos diferentes, según el modelo que Juan David Nasio plantea en su ensayo El libro del dolor y del amor, sostiene el psicoanalista argentino afincado en Francia que en el dolor psíquico provocado por la ruptura súbita de una unión o lazo íntimos aparecen en secuencia

un dolor propio de la ruptura, luego un dolor inherente al estado de conmoción y por último un dolor suscitado por la defensa refleja del yo en respuesta a la perturbación. Desde luego, estos tres dolores no son en realidad sino los diferentes aspectos de un solo y único dolor, formado instantáneamente (Nasio 2015: 26). 
En el caso del personaje de Mella, el hombre no solo experimenta estos tres tiempos (el de la ruptura, el de la conmoción y el de la reacción defensiva) sino que los vive como si estuvieran multiplicados por dos: el dolor de la pérdida en él se duplica, y crece como un monstruo interior, a causa del fallecimiento de la hija, que sigue a la ya comentada ruptura conyugal.

\section{III - El nuevo drama: una "muerte casi cierta»}

Como ya se ha adelantado, el protagonista masculino es el único testigo del fallecimiento de su propia hija; el lector sigue la peripecia familiar a través de la descripción de los últimos días de la niña, junto a su padre en la casa de éste, ubicada cerca de un arroyo (ya se ha comentado que la historia se desarrolla en la pequeña urbanización de Neptunia). La elección de Mella de ubicar la trama a orillas de un pequeño río confirma la predilección casi bachelardiana del escritor montevideano por colocar los dramas humanos de sus criaturas ficcionales en espacios caracterizados por la presencia del agua; baste como ejemplo el cuento "La gota" (que se incluye en la edición de Noviembre de 2010), en que la preocupación del lector por la suerte de los dos protagonistas - un padre con su hijo - aumenta a medida que las aguas del río crecen hasta convertirse en una trampa mortal para los dos personajes ${ }^{4}$. Casi todos los antihéroes de Mella parecen estar vinculados al agua en cuanto elemento asociado a una muerte lenta, que va creciendo silenciosa en las entrañas de la historia misma. En particular, la sensación que tiene el lector de que siempre se guarda una parte de un secreto detrás de la superficie del texto es el reflejo, en la forma, de la presencia silenciosa y latente de un peligro mortal en el contenido de lo narrado. Esta asociación entre el auga y el peligro (es decir, la muerte al acecho) se pone de relieve precisamente en las reflexiones de Gaston Bachelard cuando el filósofo francés señala cómo uel ser consagrado al agua es un ser en el vértigo. Muere a cada minuto, sin cesar algo de su sustancia se derrumba. [...] El agua corre siempre, el agua cae siempre, siempre concluye en su muerte horizontal" (Bachelard 2003: 15).

Ahora bien, en Noviembre, en la casa frente al arroyo, Guzmán es un user en el vértigo" precisamente porque es el único miembro de la familia que conoce el horror, pues solo él tiene informaciones adquiridas empíricamente: es el único sujeto de la trama que es consciente de que la muerte de Maite acontece antes de la desaparición de su

${ }^{4}$ Así Mella relata, en "La gota", el paulatino crecer de la amenaza representada por el agua (la lluvia y el río) que va cercando el chalet de los dos protagonistas: "Los siete días y noches que siguieron no paró de llover, salvo por algunos momentos, con una paciencia insoportable. El suelo primero se infló como un globo y luego pareció desinflarse a medida que iba cubriéndose de charcos. [...]. El río ganó terreno, arrasó con la maleza y las acacias, casi cubriendo los árboles más bajos. [...] Miré al cielo. Dios estaba detrás de las nubes. Le hablé. Y le hablé al dios en las nubes mismas y al dios en cada gota manifestado" (Mella 2010: 99-100). 
cuerpo, sustraído por Javier, un conocido de Guzmán. El hombre aprovecha una ausencia de Guzmán - unas pocas horas después de que éste descubriera que el cuerpo de Maite ya no tiene vida - y desaparece con el cadáver. $O$, al menos, esto es lo que las escuetas descripciones de la situación inducen a suponer.

Mientras el resto de la familia se dedica, con la ayuda de la policía local, a una infructuosa búsqueda de la niña, Guzmán se aleja anímica y espacialmente de este afán detectivesco y se ubica en el rol de quien ya es consciente de que la pérdida es definitiva; sus pensamientos se hunden en los vericuetos metafísicos que le llevan a meditar sobre el "momento-umbral", sobre cuál es el instante en que se da el tránsito entre la salud y la enfermedad:

Recordó esa sensación, hoy. Lo llevó a pensar en Maite yéndose, y se preguntó si era posible precipitarse de un estado a otro sin notarlo. Trató de intuir si se podía señalar un instante exacto del mismo modo en que podía señalarse un día como el día de cierta toma de decisión, o el día en que la enfermedad sustituyó la salud. Pero siempre en esos casos se atravesaba una crisis profunda, que podía o no desarrollarse a escondidas, un germen reptando en las márgenes de la conciencia. $Y$ el hecho de que la muerte llevara creciendo dentro de su hija igual que una bacteria y desde quién sabe cuándo, lo abrumó (Mella 2010: 30).

Esos sentimientos "negativos", esas imágenes que remiten a la idea de una lenta destrucción desde dentro (la muerte es imaginada como una presencia que lleva creciendo dentro de su hija, como una bacteria) no transmiten ya solo la morbosa fascinación por el horror, sino un sentir nuevo, igualmente desgarrador: hasta ese momento, el hombre solo había sido testigo del camino que lleva hacia el fin a las víctimas de la muerte-bacteria; ahora, se suma una dimensión casi metafísica, que involucra tanto la intensidad de los afectos como su transposición a la materialidad del cuerpo: Guzmán y Ana se preguntan si supieron empeñarse hasta lo extremo para hacer que su hija no se fuera:

Guzmán ve a Ana a contraluz, real y cerca. Y recupera la noción que le surgía cuando estaban juntos y el tiempo producía un hueco para ellos y se descolgaban de la nada para conocerse ahí limpios del mundo, que se tornaba estéril y sombrío. Ana dice, - ¿Nosotros la queríamos? - ¿Cómo? - Digo, ¿la queríamos de verdad? No hicimos nada para tenerla. No sé. - No sabes lo que estás diciendo, dice Guzmán (Mella 2010: 56).

La observación de Ana desata en Guzmán la reflexión acerca de la lentitud del proceso que marca el tránsito entre la presencia física en el mundo de un ser humano y su desaparición. Elucubrar acerca de los mecanismos que hacen que un individuo se haga 
cenizas responde a la exigencia del hombre de medir el tiempo de su aniquilación y parece remitir, de nuevo, al análisis bachelardiano de la lentitud de la descomposición:

Todo lo que la muerte tiene de pesado, de lento, está también marcado por la figura de Caronte. [...] La muerte es un viaje que nunca termina, una perspectiva infinita de peligros. [...] La barca de Caronte es, pues, un símbolo ligado a la indestructible desgracia de los hombres, que atraviesa las edades del sufrimiento (Bachelard 2003: 123-124).

Obsérvese cómo el viaje sin fin de Caronte es metáfora de la lentitud de la muerte, aplicada a la enfermedad silenciosa de Maite, y alude simbólicamente al acto de cruzar un río; es decir, remite a la imagen del cuerpo sustraído a los padres, que no han podido (o sabido) protegerlo. No es secundario, además, subrayar cómo Guzmán - en su dolor invierte los términos del horror: la indestructible desgracia de los hombres (que consiste no solo en la muerte infinita, sino también - en lo práctico - en el sentido de culpa de quien sobrevive) se vuelve para él un desvarío de su ex pareja, quien "no sabe lo que está diciendo". Hay, en esta condición, la evidencia de la dificultad de indagar en la conciencia de uno mismo.

En aquellas escasas situaciones en las que Guzmán participa en las operaciones de búsqueda de su hija, se ve reflejada su percepción de la muerte de Maite como una suerte de monstruo, esto es, como una "presencia con rostro": el hombre no sabe comprender cómo ha sido posible que esa joven vida se haya ido apagando mediante una lenta, oculta y silenciosa degradación del cuerpo, y en su proceso de búsqueda la muerte aparece corporizada, como en un espejo; el hombre persigue gestos, facciones, semblantes de su hija fallecida en todo lo que ve a su alrededor:

Detuvo el auto en la plaza principal y miró a los chicos que jugaban en la pista de skate, siguió los rostros, las espaldas, las rodillas del buen número de gente que cruzaba en dirección a la parte vieja de la ciudad. Buscó un gesto, un rasgo, el color de algunas de las facciones de Maite, algún detalle en el movimiento de las manos (Mella 2010: 52).

Los apartados de la novela en que se describe la búsqueda que el hombre emprende de algún rasgo físico de la hija perdida remiten al funcionamiento de la psique humana en relación opuesta con el principio del placer: en líneas generales, todo proceso psíquico se apoya en este principio, que es una suerte de "mecanismo" capaz de regular la intensidad de las tensiones y pulsiones, y de hacerlas tolerables. Ahora bien, en el momento en que se verifica una ruptura traumática, un corte abrupto y brutal con el ser amado, este principio deja de ser una defensa: las tensiones se desencadenan y el efecto regulador se desvanece. El dolor expresa, así, la autopercepción de una tensión imposible de modular y controlar, que se refleja en la persecución de gestos, rasgos y facciones del ser desaparecido; esta dinámica expresa lo inmanejable que se vuelve el dolor, tal como 
recuerda Nasio: “el dolor es el afecto que expresa en la conciencia la percepción por parte del yo [...] del estado de shock, del estado de conmoción pulsional (trauma) provocado por la ruptura, no de la barrera periférica del yo, como en el caso del dolor corporal, sino por la ruptura súbita del lazo que nos vincula con el otro elegido. El dolor es aquí dolor del trauma" (Nasio 2015: 32).

En este análisis del dolor del trauma, Mella no descuida tampoco enfrentarse a la perspectiva de la madre de Maite; la mirada femenina adulta transita también por la fase de desaparición del mecanismo de defensa al que alude Nasio y se construye, de nuevo, en torno al proceso de rememoración; ante el drama de la ausencia (una ausencia que en el caso de Ana refleja la duda de si Maite ha desaparecido o se ha muerto), la mente se alimenta del recuerdo de instantes del pasado; Maite vuelve a aparecer delante de los ojos de su madre en la rememoración de un viaje-premio que la familia, entonces unida, había ganado unos años atrás a la costa de Rocha:

Ana fuma como una experta y recuerda cuando Maite los obligaba a cerrar los ojos y entonces pasaban a estar en Rocha. Decía: Ahora nos vamos a poner las chancletas porque puede haber algún anzuelo por ahí, vamos a ponernos el gorro, vamos a sacarnos la arena de los pies, vamos subiendo despacito, escalón por escalón (Mella 2010: 58).

\section{IV - Y al final, el estado depresivo impacta en la expresión}

En el protagonista masculino se hace patente una agitación constante de la mente, que refleja un estado anímico depresivo continuo: se trata de una condición que se manifiesta en el intento complejo no ya de evadirse de la realidad (la separación, la enfermedad y desaparición de la hija), sino en una suerte de constante enfrentamiento con el gran fantasma de la muerte. En el marco de este enfrentamiento, la indeterminación de lo dicho y la presencia constante de varias hipótesis plausibles al mismo tiempo, parecen ser, en conjunto, el reflejo - en la hoja de papel - de la inestabilidad emotiva de Guzmán. Y la cámara que parece seguirlo, que traslada al lector sus gestos, sus silencios, sus tambaleos introspectivos, se encarga de convertirse en un narrador-testigo caracterizado por ofrecernos descripciones incompletas o ambiguas.

Insistir en que la escritura de Mella se presenta como una uescritura de espacios vacíos", significa afirmar que existe en el fondo de su acto escritural un sistema de tensiones entre lo legible y lo ilegible; es decir, entre la necesidad, por un lado, de transmitir al lector una base mínima de nociones para seguir la trama $y$, por otro lado, reflejar una específica productividad estética caracterizada por aquellos pequeños secretos que ocultan una parte de lo acontecido. Para comprender la centralidad de este punto en una novela como Noviembre conviene recordar que la información le llega al lector a través de la palabra-imagen que el narrador proyecta; y que a menudo estas 
"descripciones" se convierten en una suerte de relación de monólogos interiores, en los que la lucidez del protagonista es ofuscada por la pérdida de sentido. Y esta pérdida de sentido remite, precisamente, a la incomprensión de los eventos por parte de Guzmán.

Ante la tragedia de la muerte, sus reflexiones introspectivas revelan un desajuste interior: la información que se desprende de sus andanzas por Neptunia y de sus elucubraciones es siempre incompleta precisamente porque el mundo a su alrededor se hace ilegible 5 . El antihéroe de Mella entra en una espiral de hastío y apatía que se traslada a la descripción que recibimos del narrador: "Guzmán siente cómo lo abandona la capacidad de asombro, y la esperanza de algo extraordinario se disipa. Queda mortalmente aburrido, con el costillar vacío, los pulmones como trapo" (Mella 2010: 53). El relato asocia lo ilegible con los "pequeños secretos", contraponiendo así lo dicho y lo no-dicho; se establece una asociación con el tema mismo del trauma visto como una experiencia indecible, un "estado" que exige ser nombrado y que sin embargo nunca llega a reflejarse en palabras, como algo para lo cual el ser humano no encuentra lugar en el lenguaje. No obstante, a esta condición se suma otra, tal como se desprende de la cita anterior: una condición por la que no sería clave lo no-dicho sino lo indecible, que se refleja al nivel corporal, y que afecta al cuerpo, pues se traslada a la descripción del cuerpo del protagonista.

La pérdida del sentido y de la capacidad de asombro representan en su conjunto el déficit de sentido al que alude Prieto; la novela se desarrolla, así, según procedimientos formales que la inscriben en el marco de una "escritura que oculta", de una textualidad que se hace precaria, y esta deriva hacia una forma narrativa deshilvanada es justamente el resultado de la ilegibilidad del mundo que percibe Guzmán. Su estado de depresión, ya presente a causa de la separación, se traslada al texto, y es "por ese deshilachado textual [que] se produce un deshacerse de la ficción en la contradictoriedad del presente" (Prieto 2016: 24). Se plantea, así, en la novela un horizonte interpretativo en el que hay dos "órdenes de rupturas" distintos. Por una parte, el déficit de sentido vinculado con la ruptura sentimental podría leerse en clave postromántica, según el modelo que sugiere Prieto: vendría a ser el resultado de un dolor expresable con descripciones introspectivas, de estados anímicos. El individuo sufre y hay como un "vacío que se llena de soledad" en su existencia. Por otra parte, con la muerte de Maite, se accede al desorden del trauma, de lo absurdo, que es inexpresable. Que solo se puede tocar ligeramente con las descripciones corporales. En fin, no es que la vida del individuo se haga ilegible: es más bien el mundo (el espacio diegético) que se vuelve un sinsentido.

${ }^{5}$ En el ensayo La escritura errante. llegibilidad y políticas del estilo en Latinoamérica, Julio Prieto se dedica a analizar la cuestión de la pérdida de sentido y de la incomprensión de los eventos, en relación con una escritura interrupta y fragmentaria; afirma Prieto que "la tradición del arte y el pensamiento moderno propone un archivo de usos y prácticas de lo ilegible que se caracteriza por poner en escena un déficit de sentido. Sería la tradición que va desde la poética romántica del fragmento al motivo postromántico del mundo como libro vacío, desde los Disparates de Goya al dadaísmo, al teatro del absurdo y al existencialismo del siglo XX" (Prieto 2016: 28-29).

BEOIBERÍSTICA Vol. II / Número 1 (2018) | 135-150 
Finalmente, con el objetivo de subrayar el fuerte estado depresivo de Guzmán, cabría concluir observando cómo - en sus reflexiones introspectivas - se vislumbra el permanente juego dialéctico de "tentar a la muerte" mediante la prefiguración de desastres, que anticipan y articulan un deseo de muerte. Así se observa en el pasaje que sigue: "No le soprendería que el suelo se abriera bajo sus pies, que las casas y edificios se derrumbaran a sus pies, no le extrañaría en lo más mínimo que toneladas de mar se alzaran de repente y le cayeran encima a todo como una pisada azul porque lo desea" (Mella 2010: 53). Adquiere así un sentido interpretativo nuevo la afirmación del personaje de Mella acerca del proceso de pudrición del cuerpo, definido en un principio como una "maravilla, superior a cualquier otra cosa del universo": no sería maravilloso el proceso en sí, sino al revés, es decir, se anhela, sí, la muerte, pero una muerte que haga desaparecer enseguida el cuerpo, oculto bajo toneladas de mar. No parece casual que sea el mar el elemento encargado de poner un fin a la existencia: una elección coherente con la poética de Mella y que remite - en el plano metafórico - a la afirmación de X. B. Saintine según la que "Sin Caronte no hay infierno posible" (Saintine 1863: 303); es decir, el elemento acuático es indisociable del elemento tanático.

\section{BIBLIOGRAFÍA}

Bachelard, Gaston. El agua y los sueños. México: Fondo de Cultura Económica, 2003. Impreso.

Bluth, Daniela. "La literatura es un espejo distorsionado de la realidad". El país Cultural, Montevideo, 26/03/2017. Web. 28 Sep. 2017.

Courtoisie, Rafael. "Real y fantástico en la narrativa iberoamericana del siglo XXI: segunda parte. Imprecisas fronteras del cielo y el infierno". Ángel Esteban y Jesús Montoya Juárez (eds.), Miradas oblicuas en la narrativa latinoamericana contemporánea. Madrid: Iberoamericana-Vervuert, 2009: 277-286. Impreso.

Derrida, Jacques. Passions. Paris: Galilée, 1993. Imprimé.

Freud, Sigmund. "Proyecto de psicología”. Obras completas, tomo 1. Buenos Aires: Amorrortu Editor, 1991. Impreso.

Laddaga, Leonardo. Estética de la emergencia. Buenos Aires: Adriana Hidalgo Editora, 2010. Impreso.

Mella, Daniel. Derretimiento. Madrid: Lengua de Trapo, 1999. Impreso.

-. Noviembre. Montevideo: Irrupciones Grupo Editor, 2010. Impreso.

—. "Daniel Mella". Página web del escritor. Web. 28 Sep. 2017.

Nasio, Juan David. El libro del dolor y del amor. Barcelona: Gedisa, 2015. Impreso.

Prieto, Julio. La escritura errante. llegibilidad y políticas del estilo en Latinoamérica. Madrid: Iberoamericana-Vervuert, 2016. Impreso. 
Rosa, Hartmut. Accelerazione e alienazione. Per una teoria critica del tempo nella tarda modernità. Torino: Giulio Einaudi Editore, 2015. Stampato.

Saintine, X. B. La Mythologie du Rhin et le contes de la mère-grand. Paris: Librairie Hachette, 1863. Imprimé.

Trujillo, Henry. "La literatura de las amenazas irracionales". José Antonio Carbonell (ed.), Ciudad y literatura: III Encuentro de Nuevos Narradores de América Latina y España. Bogotá: Edición del Convenio Andrés Bello, 2004: 193-200. Impreso.

Fecha de recepción: 02 de noviembre de 2017. Fecha de aceptación: 12 de abril de 2018. 